Future trends and research issues of technology-enhanced language learning: A technological perspective

Di Zou

Haoran Xie

The Education University of Hong Kong, Hong Kong

Fu Lee Wang

The Open University of Hong Kong, Hong Kong

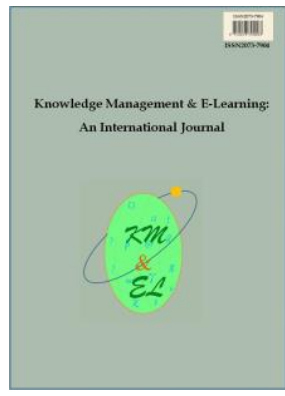

Knowledge Management \& E-Learning: An International Journal (KM\&EL) ISSN 2073-7904

Recommended citation:

Zou, D., Xie, H., \& Wang, F. L. (2018). Future trends and research issues of technology-enhanced language learning: A technological perspective. Knowledge Management \& E-Learning, 10(4), 426-440. 


\title{
Future trends and research issues of technology-enhanced language learning: A technological perspective
}

\section{Di Zou}

Department of English Language Education

The Education University of Hong Kong, Hong Kong

E-mail: dzou@eduhk.hk

\author{
Haoran Xie* \\ Department of Mathematics and Information Technology \\ The Education University of Hong Kong, Hong Kong \\ E-mail: hxie@eduhk.hk
}

\section{Fu Lee Wang}

School of Science and Technology

The Open University of Hong Kong, Hong Kong

E-mail: philipsfuleewang@gmail.com

*Corresponding author

\begin{abstract}
With recent advancements in information technologies and language learning models, rapid innovations of technology-enhanced language learning have been widely witnessed by research communities and educational institutions globally. Powerful new technologies, such as social media and networks, mobile applications, wearable computing, cloud computing, and virtual reality have been integrated into language learning to facilitate various aspects, such as interactivity, immediacy, and authenticity. In this study, we present the Future TELL Model considering learning objectives, theories, and strategies by briefly reviewing recent progresses in this area. Future trends and research issues in technology-enhanced language learning are also discussed in relation to cutting-edge technologies, such as deep neural networks, which have not yet been fully recognized by education technology communities.
\end{abstract}

Keywords: Future language learning; Technology-enhanced language learning; Deep neural networks

Biographical notes: Dr. Di Zou is an Assistant Professor at The Education University of Hong Kong. She received her Ph.D. in English from the City University of Hong Kong, and MA in Linguistics, BA in English, and BBA from the Huazhong University of Science and Technology. Her research interests include second language acquisition, computer-assisted language learning, and e-learning systems. She has published more than 30 research papers in many prestigious journals and conferences. She has been a guest editor of the International Journal of Distance Learning Technologies (IJDET) and the International Journal of Innovation and Learning (IJIL), the book editor of Current Developments in Web-Based Learning, co-chairs of GCCCE, UMLL, IWUM, AADI, and ETLL, and a PC member of DLSA, SETE, ICWL, and GCCCE. She is also a member of TESOL and EUROCALL. 
Dr. Haoran Xie is an Assistant Professor at The Education University of Hong Kong. He received his Ph.D. and M.Sc. from the City University of Hong Kong, and BEng. from the Beijing University of Technology. His research interests include machine learning, big data, and educational technologies. He has published over 125 publications, including 45 papers in reputable journals, such as IEEE Transactions on Affective Computing, IEEE Intelligent Systems, Neural Networks, Knowledge-Based Systems, Information Processing and Management, Information Sciences, Neurocomputing, Educational Technology $\&$ Society, etc. He has been a guest editor of eight journals and cochair/committee member of more than 50 international conferences, such as WI IEEE TALE, APWeb-WAIM, SETE, CPSCom, GCCCE, U-Media, WISE, and ICWL.

Dr. Fu Lee Wang is a Full Professor and Dean in the School of Science and Technology at the Open University of Hong Kong. He received his BEng. and M.Phil. from The University of Hong Kong, M.Sc. from The Hong Kong University of Science and Technology, MBA from Imperial College London, and Ph.D. from The Chinese University of Hong Kong. His research interests include information retrieval, information systems, e-business, e-learning, and financial engineering. Prior to joining OUHK, he was a Full Professor at the Caritas Institute of Higher Education, and a faculty member at the City University of Hong Kong. He has over 200 publications and has received 20 grants with a total of more than $\$ 20$ million HKD.

\section{Introduction}

With the rapid advancement of information technologies, such as augmented/virtual reality (Wu, Lee, Chang, \& Liang, 2013), wearable computing (Ngai, Chan, Cheung, \& Lau, 2010), mobile applications (Hwang \& Wu, 2014), cloud-computing applications (Bora \& Ahmed, 2013), social media (Dizon, 2016; Sun, Lin, You, Shen, Qi, \& Luo, 2017) and big data processing (Picciano, 2012), great innovation and transformation of technology-enhanced learning have occurred in recent years. Moreover, the fast development of various technology-enhanced pedagogies, including the flipped classroom (Chen Hsieh, Wu, \& Marek, 2017), gamification (Calvo-Ferrer, 2017) and socio-cultural contexts (Wang, Liu, \& Hwang, 2017) that have been adopted in language learning, has become another important aspect for augmenting the ubiquity of technology-enhanced language learning (TELL). Extant variety in both technologies and pedagogies also provides flexible options for the implementation of TELL in classroom teaching and learning, as well as out-of-class learning activities.

Despite the variety in the transformation of TELL, some distinct trends of TELL have been identified. For example, contextual learning of language in certain socialcultural contexts constitutes an essential stream of TELL, as identified by Wang, Liu, and Hwang (2017). Golonka, Bowles, Frank, Richardson, and Freynik (2014) found that technologies that support instant feedback can improve students' language learning efficiency. However, these investigations may focus only on a specific new trend of TELL, and no unified framework has yet been provided as a roadmap to identify different trends of future development of TELL. Therefore, in this article, we propose the Future TELL Model (FTM) from dimensions of learning objectives, theories, technologies, and strategies by briefly reviewing recent progresses in this area. The FTM will elucidate the development and future trends of each dimension. For example, in the case of learning objectives, recent TELL studies mainly comprise three aspects, which are: (1) language 
knowledge acquisition; (2) integrated use of language; and (3) social-cultural context learning. The details of FTM will be presented in Section 3.

Another important aspect is that a gap exists between the development of technologies and education technology applications, as identified by Goldin and Katz (2009). To bridge this gap, it is critical to investigate recent advancements in technologies and determine which cutting-edge research findings can be most advantageously applied to TELL. In this article, future trends and research issues in TELL are also explored based on advanced technologies that have not yet been well noted by education technology communities. In particular, we selected certain technologies, such as deep neural networks (Glorot \& Bengio, 2010; Silver et al., 2016), which offer great potential for TELL. The remainder of this article proceeds as follows. In Section 2, a literature review of TELL is performed. Section 3 mainly introduces the Future TELL Model for summarizing recent trends in this area. Section 4 discusses future trends and some research issues from a technological perspective. In Section 5, the findings of this article are summarized.

\section{Literature review}

Since some extant literature (Golonka et al., 2014; Wang, Liu, \& Hwang, 2017) focuses on technology types and socio-cultural contexts in language learning, the literature review in this section considers more recent developments in other aspects of TELL. These recent literatures will be organized into the following specific topics.

\subsection{Collaborative learning in TELL}

Collaborative learning in TELL refers to the use of technology to support collaboration between students and teachers in language learning activities (Lin, Zheng, \& Zhang, 2017). Angelova and Zhao (2016) adopted computer-mediated communication tools to facilitate second-language acquisition and develop English as a second language teaching skills and cultural awareness through a collaborative online project between students from China and the U.S.A. Amiryousefi (2017) investigated the effects of three types of prewriting planning conditions, including teacher-monitored collaborative planning, student-led collaborative planning, and individual planning on English as a Foreign Language (EFL) learners' computer-mediated L2 writing tasks. Kuo, Chu, and Huang (2015) developed an online collaborative platform to examine the effects of group learning based on learning styles of group members for English language learning. To confirm whether or not students with different levels of language proficiency can benefit equally from collaborative learning, Huang, Liu, Wang, Tsai, and Lin (2017) implemented a long-term technology-enhanced collaborative storytelling activity, and examined young students' pair performance, flow perception, and learning strategies in relation to students' English proficiency level.

\subsection{Flipped learning in TELL}

The flipped mode has been popular in TELL due to its high dependence on technologies. To determine the benefits of the flipped classroom model for second language learners, Chen Hsieh et al. (2017) employed the Output-driven/Input-enabled model (Wen, 2008) to design an oral training course for learning English idioms. Adnan (2017) compared the impact of flipped classrooms and non-flipped classrooms for second language learners regarding academic outcomes and students' perceptions of their learning experience. 
Hung (2015) integrated flip teaching into language classrooms using a WebQuest active learning strategy to study the possible impacts of flipping the classroom on English language learners' academic performance, learning attitudes, and participation levels. Huang and Hong (2016) investigated the effects of a flipped English classroom on high school students' information and communication technology, and English reading comprehension. Yu and Wang (2016) examined the effectiveness of the flipped model in a business English writing course by adopting a clicker-aided approach.

\subsection{Game-based learning in TELL}

To better motivate English language learners and facilitate their language learning, an increasing number of games have been developed for language enhancement. The results of research on game-based language learning generally share two conclusions: (1) games have positive effects on motivation (Garris, Ahlers, \& Driskell, 2002; Graesser, Chipman, Leeming, \& Biedenbach, 2009; Brom, Preuss, \& Klement, 2011; Connolly, Stansfield, \& Hainey, 2011; Chen \& Yang, 2013); and (2) games promote effective vocabulary learning (Abrams \& Walsh, 2014; Smith et al., 2013; Yu \& Guan, 2013; Chou, 2014; Pasfield-Neofitou, 2014; Calvo-Ferrer, 2017; Wu \& Huang, 2017). Another typical strength of games, which is conducive to language learning, is their interactive feature (Konradt \& Sulz, 2001; Lim, Nonis, \& Hedberg, 2006). Some researchers also report that games promote critical thinking skills (Ke, 2008; Ke, 2014; Papastergiou, 2008), and others found that certain games can create virtual environments or realistic sociocultural contexts that facilitate language learning (Schwienhorst, 2002; Anderson, Reynolds, Yeh, \& Huang, 2008; Rankin, Morrison, McNeal, Gooch, \& Shute, 2009; Young et al., 2012; Zheng, Young,Wagner, \& Brewer, 2009; Zheng, Bischoff, \& Gilliland, 2015).

\subsection{Mobile learning in TELL}

With the development of mobile devices and wireless technology, mobile-assisted language learning (MALL) has been increasingly utilized by English language learners and educators (Wu \& Huang, 2017). One of the most common research topics in this field is students' perceptions towards mobile learning technologies. Numerous researchers have demonstrated that students hold very favourable attitudes towards MALL (Chen \& Hsu, 2008; Basoglu \& Akdemir, 2010; Chang, Tseng, Liang, \& Yan, 2013; Hsu, 2013; Liu \& Chen, 2015; Lin, 2017; Shadiev, Hwang, \& Huang, 2017). Many studies also showed that MALL is advantageous in creating authentic materials, activities, and environments to promote language learning.

\section{The future TELL model}

In this section, we introduce the Future TELL Model (FTM), as shown in Fig. 1. Specifically, the FTM contains three dimensions, which are: (1) learning objectives; (2) learning strategies; and (3) learning theories. The remaining parts of this section will detail the components and features of each dimension.

\subsection{Learning objectives}

As shown in Fig. 1, the dimension of learning objectives comprises four aspects which are: (1) simple acquisition of language knowledge; (2) integrated acquisition of language knowledge; (3) integrated use of language knowledge; and (4) use of language 
knowledge in socio-cultural contexts. One classification method that distinguishes these four aspects is to map each aspect to a category of Bloom's taxonomy (Krathwohl, 2002), which is a widely adopted method for classification of learning objectives. Specifically, the simple/integrated acquisition of language knowledge corresponds to the categories of "remember" and "understand", while "the integrated use of language knowledge" and "the use of language knowledge in socio-cultural contexts" correspond to the category of "apply" and "create".
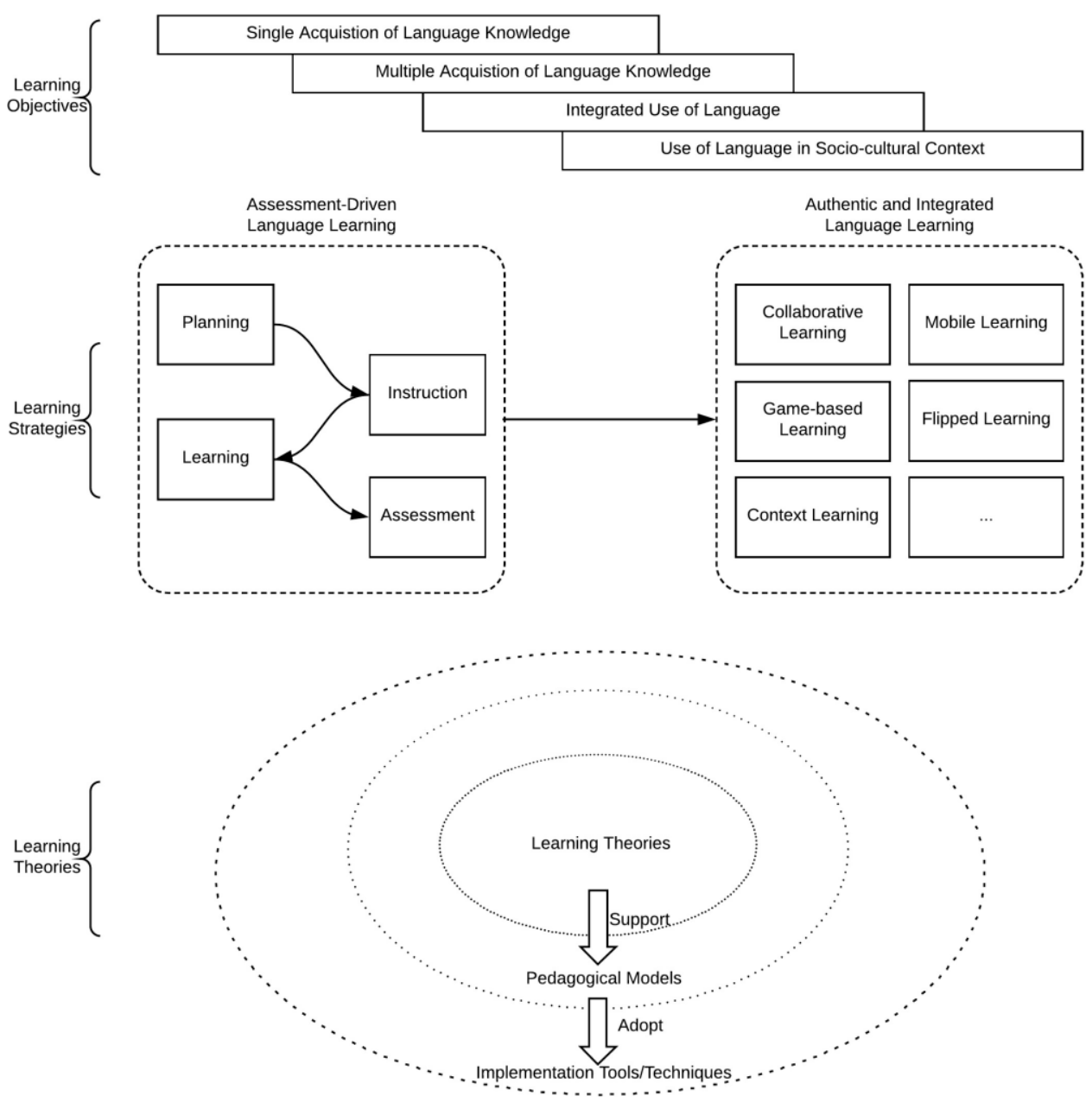

Fig. 1. The future TELL model (FTM)

However, it is difficult to precisely classify these four aspects by using Bloom's taxonomy. To overcome this limitation, we further introduce two factors, "authenticity of context" and "degree of integration", for these four aspects. The first factor, "authenticity of context", refers to the degree of authenticity of language learning contexts created or facilitated by technologies in learning tasks. For example, certain technologies, such as augmented/virtual reality (Schwienhorst, 2002), social networks (Dizon, 2016), and 
virtual collaborative platforms (Angelova, \& Zhao, 2016) can assist educational researchers and teachers to create authentic contexts for language learning (e.g., create a virtual scenario for language speaking at a coffee shop). The utilization of mobile applications to engage students in a language learning system to complete reading comprehension tasks can be considered as "learning in an artificial context" (in this example, the article in the reading comprehension). Semi-authentic contexts are combinations of authentic contexts and artificial contexts. For example, learning tasks in a role-playing game (RPG) are established as fill-in-the-blank or reading comprehension tasks. The entire story background of this RPG is an authentic context, and the tasks in the game constitute artificial contexts.

The second factor, "degree of integration", denotes the degree of integrated application and use of various aspects of language knowledge and skills. Integrated language learning has been confirmed as an effective method for language acquisition in linguistic studies (Mehisto, Marsh, \& Frigols, 2008). In addition, approximately three levels of integration exist. If a TELL activity only aims to acquire one specific aspect of knowledge about the language, this TELL activity is considered as "no integration". An example of "no integration" in TELL is vocabulary meaning acquisition (Chen \& Hsu, 2008), which focuses on how to adopt MALL to assist students to remember word meaning. Semi-integration refers to TELL activities that involve a few aspects of language knowledge (e.g., an essay writing task involves both syntactical and vocabulary knowledge). However, integration here remains limited, as these TELL activities cannot help learners to link knowledge to appropriate contexts (Wang, Liu, \& Hwang, 2017). If TELL activities can enable learners not only to understand various aspects of knowledge but also to apply the knowledge in certain contexts, these activities are categorized as "full integration".

Table 1

Two factors for four aspects of learning objectives in FTM

\begin{tabular}{lcc}
\hline & Authenticity of context & Degree of integration \\
\hline $\begin{array}{l}\text { Simple acquisition of } \\
\text { language knowledge }\end{array}$ & $\begin{array}{c}\text { No context or artificial } \\
\text { context }\end{array}$ & No integration \\
$\begin{array}{l}\text { Integrated acquisition of } \\
\text { language knowledge }\end{array}$ & $\begin{array}{c}\text { No context or artificial } \\
\text { context }\end{array}$ & Semi-integration \\
$\begin{array}{l}\text { Integrated use of language } \\
\text { knowledge }\end{array}$ & Semi-authentic context & Full integration \\
$\begin{array}{l}\text { Use of language knowledge } \\
\text { in socio-cultural contexts }\end{array}$ & Authentic context & Full integration \\
\hline
\end{tabular}

The details of how each aspect corresponds to these two factors are presented in Table 1. It is worth noting that the nature of contexts is not important in the second factor. The only distinction between "integrated use of language" and "use of language in sociocultural contexts" is whether or not the context is authentic. Recently, many investigations have focused on identifying ways to assist learners to understand language in socio-cultural contexts (Wang, Liu, \& Hwang, 2017; Shadiev, Hwang, Huang, \& Liu, 2018). 


\subsection{Learning strategies}

Various learning strategies exist in TELL research, which can be further divided into two streams, as shown in the second dimension of Fig. 1. One stream is assessment-driven language learning, which adopts technologies to improve the effectiveness one or more learning phases of the assessment-driven learning cycles (i.e., planning, instruction, learning, and assessment). A typical example is to utilize computer-assisted tests for assessing language knowledge, such as vocabulary size (Tseng, 2016) or listening capability (Wei \& Zheng, 2017).

Another stream of TELL research comprises flipped language learning, gamebased language learning, collaborative language learning strategies, etc. We categorize these learning strategies as "authentic and integrated language learning" because these strategies attempt to employ technologies in various aspects of language knowledge in more authentic contexts. As shown in the second dimension in Fig. 1, an arrow is added between "assessment-driven language learning" to "authentic and integrated language learning". This arrow indicates that a growth trend exists concerning performing more research about the latter category of language learning strategies instead of the former one.



Fig. 2. The trend of publications in these two categories of learning strategies

As shown in Fig. 2, we collected language learning related articles from six reputable journals (i.e., Computer \& Education, Educational Technology \& Society, Interactive Learning Environment, British Journal of Education Technology, Education Technology Research and Development, and Computer Assisted Language Learning) from 2015 to 2017. These publications are then categorized into two categories of learning strategies, as mentioned. In all three years, the number of publications in the "authentic and integrated language learning" category is greater than, or equivalent to, the number of publications in the "assessment-driven language learning" category. Although this finding may not be indicative of all publications from all TELL-related research communities, the data still identify a growth trend of publications in the second category of learning strategies, as the selected six journals are well-established and commonlyselected journals in review studies (Wang, Liu, \& Hwang, 2017; Shadiev, Hwang, \& Huang, 2017; Fu \& Hwang, 2018). 


\subsection{Learning theories}

As shown in the third dimension in Fig. 1, the framework of learning theories in TELL can be classified into three layers: (1) learning theories; (2) pedagogical models; and (3) implementation tools/techniques. Moreover, the relationships among these three layers are that: (1) pedagogical models are supported by learning theories; and (2) techniques or tools are adopted to implement the pedagogical models.

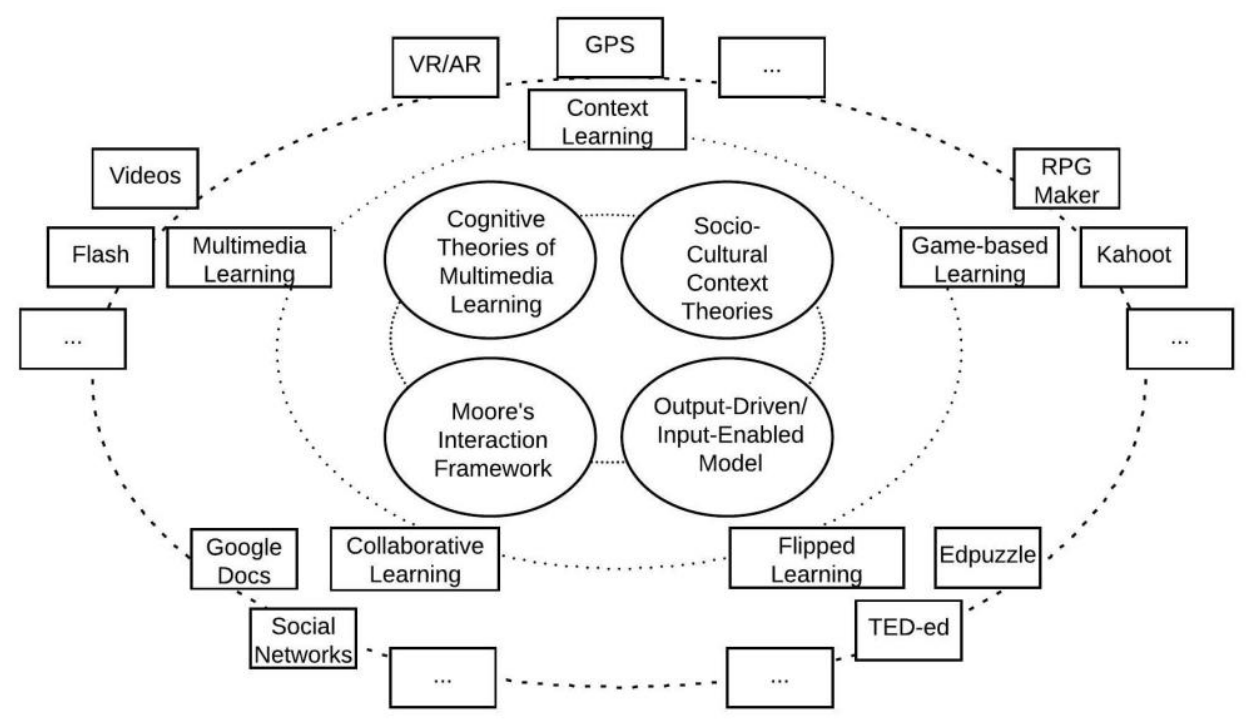

Fig. 3. The details of the three-layer framework of learning theories in FTM

As shown in Table 2 and Fig. 3, Moore's (1989) interaction framework, which includes three types of interactions (i.e., learner-learner interaction, learner-instructor interaction, and learner-content interaction) constitutes an important theory for collaborative language learning. Collaborative language learning can be facilitated and implemented by cloud-based collaborative software tools, such as Google Docs (Ebadi \& Rahimi, 2017) or social network platforms (Dizon, 2016). Mayer's (2009) cognitive theories of multimedia learning, which are based on three assumptions (i.e., the dual channel, limited capacity, and active processing), provides a guideline for designing instructions under a multimedia environment (Jiang, Renandya, \& Zhang, 2017). Multimedia language learning can be implemented by online videos, flash, animations, or other multimedia tools/applications. Socio-cultural context theory claims that learners' knowledge will be more actively constructed and exchanged through socio-cultural interactions related to specific social settings (Vygotsky, 1978; Kumpulainen, Karttunen, Juurola, \& Mikola, 2014; Wang, Liu, \& Hwang, 2017). This theory provides strong support for context language learning and game-based learning. Certain tools/techniques, such as virtual/augmented reality (Schwienhorst, 2002), location-based systems (Wang, Liu, \& Hwang, 2017), RPG Maker (Hwang, Hsu, Lai, \& Hsueh, 2017), and Kahoot (Adnan, 2017) can be employed to implement the above two learning modes. The Output-driven/Input-enabled model, which provides a theoretical basis for flipped 
language learning, asserts that "input enables learners to produce output, and output drives learners to pursue input" (Wen, 2008).

Table 2

Learning theories framework for TELL in FTM

\begin{tabular}{|c|c|c|}
\hline Learning Theories & Pedagogical Models & Implementation Tools/Techniques \\
\hline $\begin{array}{l}\text { Moore's Interaction } \\
\text { Framework }\end{array}$ & Collaborative Learning & $\begin{array}{l}\text { Cloud-based Collaborative Tools } \\
\text { (e.g., Google Docs, Padlet) }\end{array}$ \\
\hline & & Social Networks, Forums \\
\hline $\begin{array}{l}\text { Cognitive Theories of } \\
\text { Multimedia Learning }\end{array}$ & Multimedia Learning & Videos, Flash, Animations, etc. \\
\hline $\begin{array}{l}\text { Socio-Cultural } \\
\text { Context Theory }\end{array}$ & $\begin{array}{c}\text { Context Learning } \\
\text { Game-Based Learning }\end{array}$ & $\begin{array}{c}\text { Virtual/Augmented Reality } \\
\text { Location-Based Systems, GPS, } \\
\text { RPG Maker, Kahoot }\end{array}$ \\
\hline $\begin{array}{l}\text { Output-Driven/Input- } \\
\text { Enabled Model }\end{array}$ & Flipped Learning & EdPuzzle, TED-ed \\
\hline
\end{tabular}

\section{Future trends and research issues}

\subsection{Pedagogical trends and issues}

Review and analysis of the extant literature indicate that future TELL will be largely characterized by such trends as hybrid pedagogies, greater authenticity, and better personalization. Based on current pedagogies (e.g., game-based learning, flipped learning, collaborative learning, multimedia learning, context learning, etc.), more hybrid pedagogies will emerge and become popularized (Lai, 2016). These will include, but not be limited to, game-based flipped learning, multimedia-enhanced context learning, flipped classrooms in collaborative environments, and game-based collaborative learning (Lan, Sung, \& Chang, 2007). These pedagogies share one factor in common: integration of multiple technology-enhanced elements that facilitate language learning. For example, with game-based flipped learning, both gamification and flipped classroom constitute this pedagogy, and it can thus better motivate learners and promote the development of higher-order thinking skills.

Another nascent trend of TELL is to develop materials and tasks with greater authenticity (e.g., Cavus \& Ibrahim, 2017). Future technologies are likely to enable learners to wear virtual reality headsets and immerse themselves in English-speaking environments to communicate with native speakers. In this way, learners' knowledge of grammar, vocabulary and the cultures of English-speaking countries, as well as listening and speaking skills, will be dramatically and rapidly improved. Similarly, social networks and cloud-based tools will provide learners with easier and more frequent interactions and collaborations (Ahn \& Lee, 2015; Chen \& Chang, 2011). In these ways, authentic communication will be realized (Huang, Shadiev, Sun, Hwang, \& Liu, 2016).

TELL will also move towards a more personalized learning experience. For example, with flipped, game-based and context learning, learners are granted greater 
flexibility; they can arrange their learning schedules, select environments, choose progress goals, and choose partners based on their own needs, preferences, and environments (Petersen, Markiewicz, \& Bjornebekk, 2009; Wang, 2017). The learning experience will become much more personalized, and learning systems will provide better feedback to individual learners (El-Bishouty, Ogata, \& Yano, 2007; Chen \& Li, 2009; Wu, Sung, Huang, Yang, \& Yang, 2011).

\subsection{Technological trends and issues}

A new revolution of machine learning technique, called "deep neural networks" or "deep learning", has been recently acknowledged in artificial intelligence communities (LeCun, Bengio, \& Hinton, 2015). The techniques of deep neural networks can be well supported by computer hardware, such as graphical processing units, due to their rapid advancement. This stream of techniques can significantly improve learning rates and adaptivity of artificial intelligence (AI). More recently, some powerful AI systems have been developed that are superior to human experts in complicated tasks, such as playing the game Go (Silver et al., 2016). However, the new wave of deep neutral networks has been rarely adopted in TELL.

A huge number of possibilities exist in TELL to adopt deep neural networks (DNN). To respond to this trend, we propose a new terminology, "DNN-based TELL", in this article. Deep Neural Networks based Technology-Enhanced Language Learning (DNN-based TELL) refers to the use of deep neural networks as a technological innovation to facilitate learning processes and create authentic environments for language learning. DNN-based TELL has a wide-range of applications.

One possibility is to employ chatbots to have conversations with learners as a dialogue-generation technique based on deep reinforcement learning (one kind of DNNbased technique), which has been proven to be both accurate and human-like (Li, Monroe, Ritter, Galley, Gao, \& Jurafsky, 2016). The utilization of DNN-based chatbots in language learning will create an authentic environment for language learning and transcend the physical and mental limitations of human tutors. Another potential application of DNN-based TELL is to use long-short term memory networks (one kind of DNN-based technique) for automatically and constantly scoring essays of students and providing them with just-in-time feedback (Taghipour \& Ng, 2016).

\section{Conclusion}

In this article, we firstly reviewed relevant studies on collaborative learning, flipped learning, game-based learning, and mobile learning in TELL. Based on the extant literature, we then introduced our three-dimensional Future TELL Model, explaining the three aspects of learning objectives, learning strategies, and learning theories explicitly one by one. Future trends and research issues were discussed afterwards from both pedagogical and technological perspectives. Future TELL pedagogies are likely to comprise powerful features, such as hybrid pedagogies, greater authenticity, and better personalization. With further technological development, language learning will move towards DNN-based TELL, which constitutes more use of deep neural networks as a technological innovation to facilitate learning processes and create authentic environments for language learning. 


\section{Acknowledgements}

This study was fully supported by the Innovation and Technology Fund (Project No. GHP/022/17GD) from the Innovation and Technology Commission of the Government of the Hong Kong Special Administrative Region, the Standing Committee on Language Education and Research (EDB(LE)/P\&R/EL/175/2), the Government of the Hong Kong Special Administrative Region, and the Funding Support to ECS Proposal (RG 23/20172018R), the Start-Up Research Grant (RG 54/2017-2018R), the Internal Research Grant (RG 63/2017-2018R), and the 2018 Dean's Research Fund to MIT Department (TFG-3) of The Education University of Hong Kong.

\section{References}

Abrams, S. S., \& Walsh, S. (2014). Gamified vocabulary: Online resources and enriched language learning. Journal of Adolescent \& Adult Literacy, 58(1), 49-58.

Adnan, M. (2017). Perceptions of senior-year ELT students for flipped classroom: A materials development course. Computer Assisted Language Learning, 30(3/4), 204222.

Ahn, T. Y., \& Lee, S. M. (2015). User experience of a mobile speaking application with automatic speech recognition for EFL learning. British Journal of Educational Technology, 47(4), 778-786.

Amiryousefi, M. (2017). The differential effects of collaborative vs. individual prewriting planning on computer-mediated L2 writing: Transferability of task-based linguistic skills in focus. Computer Assisted Language Learning, 30(8), 766-786.

Anderson, T. A. F., Reynolds, B. L., Yeh, X. P., \& Huang, G. Z. (2008). Video games in the English as a foreign language classroom. In Proceedings of the IEEE International Workshop on Digital Game and Intelligent Toy Enhanced Learning (pp 188-192).

Angelova, M., \& Zhao, Y. (2016). Using an online collaborative project between American and Chinese students to develop ESL teaching skills, cross-cultural awareness and language skills. Computer Assisted Language Learning, 29(1), 167185.

Basoglu, E. B., \& Akdemir, O. (2010). A comparison of undergraduate students' English vocabulary learning: Using mobile phones and flash cards. The Turkish Online Journal of Educational Technology, 9(3), 1-7.

Bora, U. J., \& Ahmed, M. (2013). E-learning using cloud computing. International Journal of Science and Modern Engineering, 1(2), 9-12.

Brom, C., Preuss, M., \& Klement, D. (2011). Are educational computer micro-games engaging and effective for knowledge acquisition at high-schools? A quasiexperimental study. Computers \& Education, 57(3), 1971-1988.

Calvo-Ferrer, J. R. (2017). Educational games as stand-alone learning tools and their motivational effect on L2 vocabulary acquisition and perceived learning gains. British Journal of Educational Technology, 48(2), 264-278.

Cavus, N., \& Ibrahim, D. (2017). Learning English using children's stories in mobile devices. British Journal of Educational Technology, 48(2), 625-641.

Chang, C. C., Tseng, K. H., Liang, C., \& Yan, C. F. (2013). The influence of perceived convenience and curiosity on continuance intention in mobile English learning for high school students using PDAs. Technology, Pedagogy and Education, 22(3), 373386.

Chen, C. M., \& Hsu, S. H. (2008). Personalized intelligent mobile learning system for supporting effective English learning. Educational Technology \& Society, 11(3), 153- 
180.

Chen, C. M., \& Li, Y. L. (2009). Personalized context-aware ubiquitous learning system for supporting effective English vocabulary learning. Interactive Learning Environments, 18(4), 341-364.

Chen, H. J. H., \& Yang, T. Y. C. (2013). The impact of adventure video games on foreign language learning and the perceptions of learners. Interactive Learning Environments, 21(2), 129-141.

Chen, I. J., \& Chang, C. C. (2011). Content presentation modes in mobile language listening tasks: English proficiency as a moderator. Computer Assisted Language Learning, 24(5), 451-470.

Chen Hsieh, J. S., Wu, W. C. V., \& Marek, M. W. (2017). Using the flipped classroom to enhance EFL learning. Computer Assisted Language Learning, 30(1/2), 1-21.

Chou, M. H. (2014). Assessing English vocabulary and enhancing young English as a Foreign Language (EFL) learners' motivation through games, songs, and stories. Education 3-13: International Journal of Primary, Elementary and Early Years Education, 42(3), 284-297.

Connolly, T. M., Stansfield, M., \& Hainey, T. (2011). An alternate reality game for language learning: ARGuing for multilingual motivation. Computers \& Education, 57(1), 1389-1415.

Dizon, G. (2016). A comparative study of Facebook vs. paper-and-pencil writing to improve L2 writing skills. Computer Assisted Language Learning, 29(8), 1249-1258.

Ebadi, S., \& Rahimi, M. (2017). Exploring the impact of online peer-editing using Google Docs on EFL learners' academic writing skills: A mixed methods study. Computer Assisted Language Learning, 30(8), 787-815.

El-Bishouty, M. M., Ogata, H., \& Yano, Y. (2007). PERKAM: Personalized knowledge awareness map for computer supported ubiquitous learning. Educational Technology \& Society, 10(3), 122-134.

Fu, Q. K., \& Hwang, G. J. (2018). Trends in mobile technology-supported collaborative learning: A systematic review of journal publications from 2007 to 2016. Computers \& Education, 119, 129-143.

Garris, R., Ahlers, R., \& Driskell, J. E. (2002). Games, motivation, and learning: A research and practice model. Simulation \& Gaming, 33(4), 441-467.

Glorot, X., \& Bengio, Y. (2010). Understanding the difficulty of training deep feedforward neural networks. In Proceedings of the Thirteenth International Conference on Artificial Intelligence and Statistics (pp. 249-256).

Goldin, C., \& Katz, L. F. (2009). The race between education and technology. Harvard University Press.

Golonka, E. M., Bowles, A. R., Frank, V. M., Richardson, D. L., \& Freynik, S. (2014). Technologies for foreign language learning: A review of technology types and their effectiveness. Computer Assisted Language Learning, 27(1), 70-105.

Graesser, A. C., Chipman, P., Leeming, F., \& Biedenbach, S. (2009). Deep learning and emotion in serious games. In U. Ritterfield, M. Cody, \& P. Vorderer (Eds.), Serious Games: Mechanisms and Effects (pp. 83-102). New York, NY: Routledge, Taylor, \& Francis.

Hsu, L. (2013). English as a foreign language learners' perception of mobile assisted language learning: A cross-national study. Computer Assisted Language Learning, 26(3), 197-213.

Huang, Y. M., Shadiev, R., Sun, A., Hwang, W. Y., \& Liu, T. Y. (2016). A study of the cognitive diffusion model: Facilitating students' high level cognitive processes with authentic support. Educational Technology Research and Development. 65(3), 505531. 
Huang, Y. N., \& Hong, Z. R. (2016). The effects of a flipped English classroom intervention on students' information and communication technology and English reading comprehension. Educational Technology Research and Development, 64(2), $175-193$.

Huang, Y. Y., Liu, C. C., Wang, Y., Tsai, C. C., \& Lin, H. M. (2017). Student Engagement in long-term collaborative EFL storytelling activities: An analysis of learners with English proficiency differences. Educational Technology \& Society, 20(3) 95-109.

Hung, H. T. (2015). Flipping the classroom for English language learners to foster active learning. Computer Assisted Language Learning, 28(1), 81-96.

Hwang, G. J., Hsu, T. C., Lai, C. L., \& Hsueh, C. J. (2017). Interaction of problem-based gaming and learning anxiety in language students' English listening performance and progressive behavioral patterns. Computers \& Education, 106, 26-42.

Hwang, G. J., \& Wu, P. H. (2014). Applications, impacts and trends of mobile technology-enhanced learning: a review of 2008-2012 publications in selected SSCI journals. International Journal of Mobile Learning and Organisation, 8(2), 83-95.

Jiang, D., Renandya, W. A., \& Zhang, L. J. (2017). Evaluating ELT multimedia courseware from the perspective of cognitive theory of multimedia learning. Computer Assisted Language Learning, 30(7), 726-744.

Ke, F. (2008). A Case study of computer gaming for math: Engaged learning from gameplay? Computers \& Education, 51(4), 1609-1620.

Ke, F. (2014). An Implementation of design-based learning through creating educational computer games: A Case study on mathematics learning during design and computing. Computers \& Education, 73, 26-39.

Konradt, U., \& Sulz, K. (2001). The experience of flow in interacting with a hypermedia learning environment. Journal of Educational Multimedia and Hypermedia, 10(1), 69-84.

Krathwohl, D. R. (2002). A revision of Bloom's taxonomy: An overview. Theory Into Practice, 41(4), 212-218.

Kumpulainen, K., Karttunen, M., Juurola, L., \& Mikola, A. (2014). Towards children's creative museum engagement and collaborative sense-making. Digital Creativity, 25(3), 233-246.

Kuo, Y. C., Chu, H. C., \& Huang, C. H. (2015). A learning style-based grouping collaborative learning approach to improve EFL students' performance in English courses. Educational Technology \& Society, 18(2), 284-298.

Lai, A. (2016). Mobile immersion: An experiment using mobile instant messenger to support second-language learning. Interactive Learning Environments, 24(2), 277290.

Lan, Y. J., Sung, Y. T., \& Chang, K. E. (2007). A mobile-device-supported peer-assisted learning system for collaborative early EFL reading. Language Learning \& Technology, 11(3), 130-151.

LeCun, Y., Bengio, Y., \& Hinton, G. (2015). Deep learning. Nature, 521, 436-444.

Li, J., Monroe, W., Ritter, A., Galley, M., Gao, J., \& Jurafsky, D. (2016). Deep reinforcement learning for dialogue generation. arXiv preprint arXiv: 1606.01541 .

Lim, C. P., Nonis, D., \& Hedberg, J. (2006). Gaming in a 3D multiuser virtual environment: Engaging students in Science lessons. British Journal of Educational Technology, 37(2), 211-231.

Lin, C. C. (2017). Learning English with electronic textbooks on tablet PCs. Interactive Learning Environments, 25(8), 1035-1047.

Lin, C. H., Zheng, B., \& Zhang, Y. (2017). Interactions and learning outcomes in online language courses. British Journal of Educational Technology, 48(3), 730-748.

Liu, P. L., \& Chen, C. J. (2015). Learning English through actions: A study of mobile- 
assisted language learning. Interactive Learning Environments, 23(2), 158-171.

Mayer, R. (2009). Multimedia learning (2nd ed.). Cambridge: Cambridge University Press.

Mehisto, P., Marsh, D., \& Frigols, M. J. (2008). Uncovering CLIL content and language integrated learning in bilingual and multilingual education. Oxford, UK: Macmillan.

Moore, M. G. (1989). Three types of interaction. American Journal of Distance Education, 3(2), 1-6.

Ngai, G., Chan, S. C. F., Cheung, J. C. Y., \& Lau, W. W. Y. (2010). Deploying a wearable computing platform for computing education. IEEE Transactions on Learning Technologies, 3(1), 45-55.

Papastergiou, M. (2008). Digital game-based learning in high school computer science education: Impact on educational effectiveness and student motivation. Computers \& Education, 52(1), 1-12.

Pasfield-Neofitou, S. (2014). Language learning and socialization opportunities in game worlds: Trends in first and second language research. Language and Linguistics Compass, 8(7), 271-284.

Petersen, S. A., \& Markiewicz, J.-K., \& Bjørnebekk, S. S. (2009). Personalized and contextualized language learning: Choose when, where and what. Research and Practice in Technology Enhanced Learning, 4(1), 33-60.

Picciano, A. G. (2012). The evolution of big data and learning analytics in American higher education. Journal of Asynchronous Learning Networks, 16(3), 9-20.

Rankin, Y. A., Morrison, D., McNeal, M., Gooch, B., \& Shute, M. W. (2009). Time will tell: In-game social interactions that facilitate second language acquisition. In Proceedings of the 4th international conference on foundations of digital games (pp. 161-168).

Schwienhorst, K. (2002). Why virtual, why environments? Implementing virtual reality concepts in computer-assisted language learning. Simulation \& Gaming, 33(2), 196209.

Shadiev, R., Hwang, W. Y., \& Huang, Y. M. (2017). Review of research on mobile language learning in authentic environments. Computer Assisted Language Learning, 30(3/4), 284-303,

Shadiev, R., Hwang, W. Y., Huang, Y. M., \& Liu, T. Y. (2018). Facilitating application of language skills in authentic environments with a mobile learning system. Journal of Computer Assisted Learning, 34(1), 42-52.

Silver, D., Huang, A., Maddison, C. J., Guez, A., Sifre, L., Van Den Driessche, G., Schrittwieser, J., Antonoglou, I., Panneershelvam, V., Lanctot, M., \& Dieleman, S. (2016). Mastering the game of go with deep neural networks and tree search. Nature, $529,484-489$.

Smith, G. G., Li, M., Drobisz, J., Park, H. R., Kim, D., \& Smith, S. D. (2013). Play games or study? Computer games in eBooks to learn English vocabulary. Computers \& Education, 69, 274-286.

Sun, Z., Lin, C. H., You, J., Shen, H. J., Qi, S., \& Luo, L. (2017). Improving the Englishspeaking skills of young learners through mobile social networking. Computer Assisted Language Learning, 30(3/4), 304-324.

Taghipour, K., \& Ng, H. T. (2016). A neural approach to automated essay scoring. In Proceedings of the 2016 Conference on Empirical Methods in Natural Language Processing (pp. 1882-1891).

Tseng, W. T. (2016). Measuring English vocabulary size via computerized adaptive testing. Computers \& Education, 97, 69-85.

Vygotsky, L. S. (1978). Mind in society: The development of higher psychological processes. Cambridge, MA: Cambridge University Press. 
Wang, H. Y., Liu, G. Z., \& Hwang, G. J. (2017). Integrating socio-cultural contexts and location-based systems for ubiquitous language learning in museums: A state of the art review of 2009-2014. British Journal of Educational Technology, 48(2), 653-671.

Wang, Y. H. (2017). Integrating self-paced mobile learning into language instruction: Impact on reading comprehension and learner satisfaction. Interactive Learning Environments, 25(3), 397-411.

Wei, W., \& Zheng, Y. (2017). An investigation of integrative and independent listening test tasks in a computerised academic English test. Computer Assisted Language Learning, 30(8), 864-883.

Wen, Q. (2008). On the output-driven hypothesis and reform of English-skill courses for English majors. Foreign Language World, 15(2), 2-9.

Wu, H. K., Lee, S. W. Y., Chang, H. Y., \& Liang, J. C. (2013). Current status, opportunities and challenges of augmented reality in education. Computers \& Education, 62, 41-49.

Wu, T. T., \& Huang, Y. M. (2017). A mobile game-based English vocabulary practice system based on portfolio analysis. Educational Technology \& Society, 20(2), 265277.

Wu, T. T., Sung, T. W., Huang, Y. M., Yang, C. S., \& Yang, J. T. (2011). Ubiquitous English learning system with dynamic personalized guidance of learning portfolio. Educational Technology \& Society, 14(4), 164-180.

Young, M. F., Slota, S., Cutter, A. B., Jalette, G., Mullin, G., Lai, B., . . Y Yukhymenko, M. (2012). Our princess is in another castle: A review of trends in serious gaming for education. Review of Educational Research, 82(1), 61-89.

$\mathrm{Yu}, \mathrm{Y} .$, \& Guan, Y. (2013). The design of English words passing game by android for middle school. Advanced Science Letters, 19(4), 1131-1135.

Yu, Z., \& Wang, G. (2016). Academic achievements and satisfaction of the clicker-aided flipped business English writing class. Educational Technology \& Society, 19(2), 298-312.

Zheng, D., Bischoff, M., \& Gilliland, B. (2015). Vocabulary learning in massively multiplayer online games: Context and action before words. Educational Technology Research and Development, 63(5), 771-790.

Zheng, D., Young, M. F., Wagner, M. M., \& Brewer, R. A. (2009). Negotiation for action: English language learning in game-based virtual worlds. Modern Language Journal, 93(4), 489-511. 